\title{
Feasibility Analysis on Flue Waste Heat Power Generation Technology of Silicon Metal Furnace
}

\author{
Dong Yang ${ }^{1,2,3, b}$, Yifei Shi, 2, 3,a , Fujun Zheng ${ }^{3, b}$, Tongyin Luan ${ }^{3, b}$. \\ ${ }^{1}$ Key Laboratory of Renewable Energy Utilization Technology in Building of National Education \\ Ministry, Jinan 250101, China \\ ${ }^{2}$ Shandong Provincial Key Laboratory of Building Energy-Saving Technology, Jinan 250101, China \\ ${ }^{3}$ School of Thermal Energy Engineering, Shongdong Jianzhu University,Jinan 250101,China \\ a491160205@qq.com, b2193416493 @qq.com
}

Keywords: Feasibility analysis; Silicon Metal Furnace; Waste heat; Power generation

Abstract. The aluminum silicon alloy production enterprises has a 25000KVA of high purity silicon metal furnace in China, 350-550 $\square$ process exhaust produced by reaction furnace is directly discharged into the atmosphere now. According to the characteristics of low temperature flue gas, such as flow rate and temperature fluctuate a great deal, silica particles in the flue gas is very fine, strong adhesion and very high resistance dust and so on, This work analyzes the feasibility of utilization of waste heat power generation. Proposed the technical scheme that use waste heat boiler of box type module structure to absorb the waste heat of the flue gas to produce medium temperature and medium pressure steam, and use spiral pole expanding motive machine to drive the generator to transform steam internal energy into high quality electrical energy. This work process is advanced and reliable, energy saving and environmental protection, has good economic benefit and social benefit, and the technology has reached the domestic advanced level.

\section{Introduction}

Industrial silicon industry is an important part of modern industry, annually consumes a lot of energy. According to statistics, the average per ton of industrial silicon consumes electric energy more than $13000 \mathrm{~kW} \cdot \mathrm{h}$, the annual production capacity of $100 \times 104 \mathrm{t}$ industrial silicon consumes electric energy more than $13 \times 108 \mathrm{~kW} \cdot \mathrm{h}$. With the establishing system of the whole society resources circulation utilization and the deepening work of energy-saving and emission reduction, as high energy consumption, waste heat recovery is imperative in industrial silicon[1]. The flue gas waste heat of industrial silicon belongs to middle and low temperature waste heat, thermodynamic level is low, waste flow is small, The waste heat parameters of the flue gas have a certain volatility and larger range. Although the residual heat from flue gas has great development potential but still has the certain difficulty. This paper will be based on a $25000 \mathrm{KVA}$ high purity silicon reactor in a Fujian aluminum silicon alloy production enterprise as an example, study waste heat power generation technology of industrial silicon furnace flue gas and analysis the economic benefit.

\section{Waste heat power generation technology example analysis}

The enterprise has a high purity silicon production lines, the main equipment is a $3600 \mathrm{KVA}$ ore heat furnace, annual yield of high purity silicon is 2600 tons, unit product energy consumption is $12500 \mathrm{kWh} / \mathrm{t}$, petroleum coke consumption per unit product is $750 \mathrm{~kg} / \mathrm{t}$. The coal washing consumption per unit product is $300 \mathrm{~kg} / \mathrm{t}$.

The ore heat furnace will produce a lot of heat in the production process. According to the calculation and experience of domestic similar enterprises, it can be supported the construction of $1800 \mathrm{~kW}$ installed capacity pure low temperature waste heat power generation system without affecting the high purity silicon reaction furnace normal work. According to analysis, we decided to eliminate the original backward production lines, and carry out technical transformation construction. Two sets $25000 \mathrm{kVA}$ high purity silicon reaction furnace will be built, 
using waste heat boiler to recover single high purity silicon reaction furnace flue gas heat, and produce saturated steam whose saturation vapor pressure is $1.5 \mathrm{MPa}$ with $16.5 \mathrm{t} / \mathrm{h}$ flow rate. Saturated steam does work after entering into the spiral pole expanding motive machine generating unit, drives the generator to generate electricity, waste steam condenses and be recovered after work, through condensate pump pressurized to the original system to achieve recycling.

\section{Thermal process scheme of waste heat power generation}

According to the site conditions, steam will be extracted in the original pipeline, accessed to 1 sets of spiral pole expanding motive machine, waste steam condenses and be recovered after work to achieve recycling. Use the steam which is discharged into the atmosphere to drive spiral pole expanding motive machine to work and output power, drive one $1800 \mathrm{~kW}$ generator. Engine works in bypass mode, if the units failure or shutdown in the run-time, there will have no affect on the original production process.

Technological process is shown in Fig.1: waste heat boiler steam drum $\rightarrow$ spiral pole expanding motive machine generating unit(drives the generator to generate electricity) $\rightarrow$ condenser(condensing into water $\rightarrow$ condensate pumps $\rightarrow$ steam drum. When the power system faults occurs to emergency stop or maintenance, automatic valve starts, surplus steam enters into the original exhaust pipe.

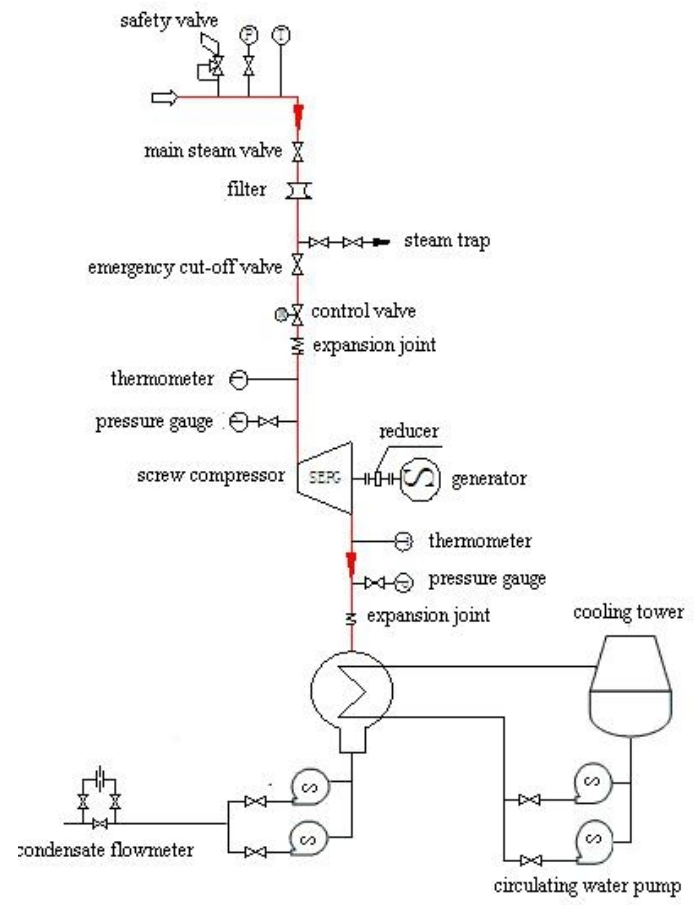

Figure 1. Thermal system diagram

Waste heat boiler. Using a set of complete natural circulation boiler in production, the rated evaporation $16.5 \mathrm{t} / \mathrm{h}$, the rated steam temperature is $198.29^{\circ} \mathrm{C}$, the rated steam pressure is $1.7 \mathrm{MPa}$. flue gas inlets into the upper part of the boiler horizontally(entrance is in the boiler rear), turns through high and low temperature superheater, evaporation section, economizer to reach dust hopper in the lower part of boiler, steers to the horizontal direction and leads out. all boiler heating surface are box type module structure, use case external insulation. Outside heat insulation layer outside protection plate is arranged to protect the insulation material. The heating surface tube is composed of a serpentine pipe platoon, from top to bottom, there are high and low temperature superheater channel, evaporator channel I , II , III, IV, economizer channel I , II , through the base ventilation beam these channels transfer their own weight to the steel frame beam. Using 
this box type structure can reduce boiler air leakage to the minimum, reduce boiler air leakage heat loss, increase the boiler heat efficiency.

Boiler feedwater flows though deaerator, then through feed water pump flows into the economizer and the top of the drum, Mixing with existing water in boiler barrel to boiler water, Through drop tube to all levels of evaporation section, steam water mixture will be generated by all levels of the evaporator outlet header of the steam water eduction tube to the drum, a steam water separation device arranged on the kettle separates saturated steam. Saturated steam from the top of the boiler barrel will be led to the low temperature superheater, by counter current steam though low temperature superheater flows into the desuperheater, after temperature reduction the saturated steam counter current flows into high temperature superheater, reaches the rated parameters though the main steam valve to power generation.

Boiler furnace wall is light holding furnace wall, furnace wall temperature is less than $50{ }^{\circ} \mathrm{C}$. Laying a small amount of refractory material in boiler internal high temperature period, such as Boiler inlet, ventilation beam etc.. To clear the dust on the heating surface of boiler, boiler ash removal system adopts the advanced steel ball ash removal system, removal dust along with smoke will flow out the boiler.

Spiral pole expanding motive machine.The spiral pole expanding motive machine type is SEPG400/600-1800/3000-1. 65-2C, rated power is $1500 \mathrm{~kW}$ and can realize stepless speed regulation. In the body the flow rate is low, so it can obtain high internal efficiency. When the refrigerant or load, waste heat, residual pressure changes it also can maintain the stability high efficiency, the operation is stable, safe, reliable.

The structure and principle is different from steam turbine, it can adapt to a variety of different quality fluid, which is the domestic only thermal power machine that can apply to the superheated steam, saturated steam, steam-water two-phase flow, hot water and high salt hot fluid now.

Screw expander host is in accordance with the principle of reverse screw compressor to work. Its basic structure and screw compressor are exactly the same, but the Work process is reversed. It has no piston machinery that valve and piston etc.. sliding parts, thus it can carry out high-speed operation and its airflow speed bigger than the ordinary volume type mechanical. It not only has the characteristics of screw compressor of high speed, good manufacturability and no wear and unbalance mass force, but also can be used for screw compressor of existing production technology to produce.

Features: the basic structure of screw expansion power machine is composed of a pair of anode and cathode of rotor, a support bearing, mechanical seal cooling water jacket, the regulating valve and the shell body composition.

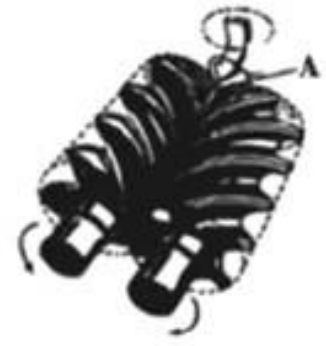

Inspiratory process

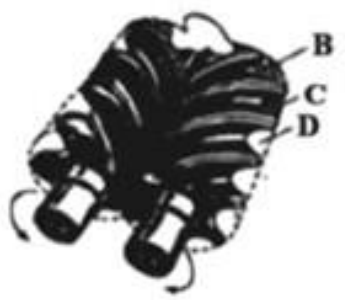

Expansion process

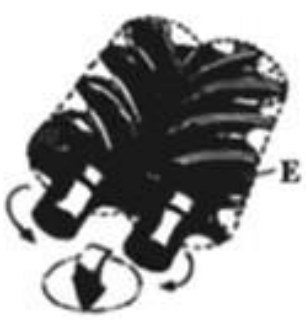

Exhaust process

Figure 2. Working process of spiral pole expanding motive machine

Its work process is shown in Fig.2: work cycle of the screw expander is composed of three suction between the volume of gear: inhale, expansion and exhaust.

Inhale in process: organic substance inflow volume A between gear from the inlet pipe, inhale at the end of the suction mouth shut, the volume A between gear is then formed a formed jointly by the rotor and the casing airtight space.

Expansion process: in high temperature and high pressure gear volume between A organic working medium volume in the expansion of the power between gear and impose A torque on the rotor. Volume of the gas between the gear with the rotation of the rotor, expanding gas moved to the 
location $\mathrm{B}, \mathrm{C}$, when gas moved to the location $\mathrm{D}$, expansion process is over, then reached the maximum volume between screw gear.

Exhaust process : Organic substance with the continuous rotation of the rotor, through volume between the gear and turned on the vent discharge.

The three process of gas suction, expansion and exhaust cycle is repeated continuously, and isothermal unceasingly, this is the working principle of screw expander. From the starting point of expansion to the finish line, as the expansion process, the gas pressure, temperature and enthalpy drop, specific volume and entropy value increases, the internal energy of the gas is converted into mechanical energy.

It has an automatic cleaning ability, does not have high requirements on the working fluid. before the working fluid flows into the body, it does not need any thermal engineering process (Such as steam expanding vessel, steam separator etc. ).

Easy operation and convenient for maintenance. The screw rotor is thick and solid, do not need major repair for a long time, minor repair is simple, operation and maintenance cost is very low and do not need special technical personnel.

Soft water cooling system. Soft water cooling system adopts self circulation cooling water. The soft water could be recycled after lowering the temperature in heat-exchanger unit though heat exchanging. The unit comes with complete set of soft water cooling system. If the user can provide soft water for recycling, the system can be omitted.

Cooling water system. In this project the equipment cooling water plans to use circulation system, cooling water circulation system comprises oil-water heat exchanger system, water-water heat exchanger system, steam-water heat exchanger system, the water is derived from the new cooling tower.

Circulating cooling water pump plans to adopt 2 single stage double suction horizontal centrifugal pump, flow: $955 \mathrm{~m} 3 / \mathrm{h}$, lift: $20 \mathrm{mH} 2 \mathrm{O}$, power: $75 \mathrm{~kW}$, one using one standby. Cooling tower plans to adopt combination counter flow mechanical ventilation cooling tower, design output: 1000m $3 / \mathrm{h}$, power: $45 \mathrm{~kW}$, water temperature difference of cooling tower will be judged by $10^{\circ} \mathrm{C}$.

\section{Process characteristics}

1.waste heat of industrial waste gas will be used, energy saving and emission reduction will be significant;

2.Put forward two stage dust removal scheme: before enters the waste heat boiler, flue gas enters the double cyclone cleaner first, it will be dust for the first time. Then flue gas enters into bag filter after heat exchanging in the waste heat boiler, it will be dust for the second time. The final emission concentration is less than $30 \mathrm{mg} / \mathrm{Nm}^{3}$, which effectively reduces the haze and meets the national requirements of atmospheric pollutant emission;

3.waste heat boiler adopts box type module structure, which has the advantages of Short installation time, high efficiency and so on;

4.The waste heat boiler uses the new tube brush type cleaning methods, it can completely remove the micro silica powder adhere on outer surface of the boiler heat exchanger tube;

Spiral pole expanding motive machine transforms the internal energy of water vapor into the mechanical energy to drive the generator to generate electricity, has the advantages of quick starting, long service life, easy operation etc.

\section{Conclusion}

Industrial silicon production is a high energy consumption industry, whether from the national policy of saving energy and reducing consumption, or the enterprise's own development, using advanced energy-saving technology, greatly reducing the consumption and production costs, and eliminating hidden trouble of safety, are the urgent problems to solve for production enterprises. The successful implementation of the waste heat power generation comprehensive utilization project, can 
optimize enterprise production system energy consumption, improve energy efficiency, reduce product cost and energy consumption, which have the vital significance to enhance the capacity for sustainable development. At the same time it plays a positive role in carrying out energy-saving emission reduction and comprehensive utilization.

\section{Acknowledgements}

This paper was financially supported by the independent innovation project of academics in Jinan(No.201401223).

\section{References}

[1] Hong-tao Shen. Discussion on Flue Gas Waste Heat Power Generation Technology of IndustrialSilicon Submerged Arc Furnace[J]. Energy and Energy Conservation, 2013(10),104-106.

[2] Zhi-hong Gao, Zhi-ming Gao.The Circular Economical Analysis and Research of Waste Heat Power Regeneration based on Silicon Metal Production[J]. Henan Electric Power, 2011(3),36-41.

[3] Hong-yun Tang, Yu-qing Liu. Glass Furnace Flue Gas Waster Heat Power Generation Technology[J]. The World of Building Materials, 2010,31(3),96-98.

[4] Rongyang Wu, Yong-lin Zhang, lili Bai. Comprehensive Utilization of Cogeneration by Airtight Flue Gas Resources from 4x30MVA Silicon Manganese[J]. Ferro-alloys, 2012,223(2),37-40.

[5] Zhichao Li, Jiading Liu, Baiping Wang. Fume Cleaning and Micro Silicon Powder Technology of the Submerged Arc Making Metallic Silicon and its Application[J]. Industrial Heating, 2007,36(4),48-50. 